2016 - Volume: 17 Number: 5

Page: 926 - 935

DOI : $10.18038 /$ aubtda. 279860

Received: 14 July 2016 Revised: 29 November 2016 Accepted: 09 December 2016

\title{
PROPERTIES OF NR AND NR/ENR BASED RUBBER COMPOUNDS REINFORCED WITH CHOPPED AND SIZED CARBON FIBER
}

\author{
Bedriye Nur YEŞiL ${ }^{1}$, Bağdagül KARAAĞAÇ ${ }^{1, ~ *}$ \\ ${ }^{1}$ Chemical Engineering Department, Engineering Faculty, Umuttepe Campus, Kocaeli University, 41380, Kocaeli, Turkey
}

\begin{abstract}
High elasticity, mechanical resistance and antivibration characteristics of natural rubber (NR) are essential issue in the main area of vehicle tyres and high modulus demanding bearing applications. In this study, especially in bearing applications, where natural rubber modulus properties are limited, natural rubber has been reinforced with chopped and hydrocarbon sized carbon fiber to get improved tensile modulus. Besides, epoxidized natural rubber (ENR), which was produced by chemical modification of natural rubber, blended with NR and the compounds have been reinforced with epoxy sized carbon fiber. NR and NR/ENR based rubber compounds' rheological, mechanical, morphological, and aging properties have been systematically investigated and evaluated.
\end{abstract}

Keywords: Carbon Fiber, Epoxidized Natural Rubber (ENR), Natural Rubber (NR), Rheological Properties

\section{INTRODUCTION}

Rubber is widely used in the production of automotive tyre, domestic appliance, shoe soles, insulation materials, anti-vibration and in seismic absorber (rubber bearing) applications [1-3]. Rubber based structure reinforcing elements, which are known as rubber bearings in general, are placed in the base of buildings; preserve the buildings and bridges from deforming effects such as sismic vibrations and acoustics. The most important performance characteristics expected from the bearings are high modulus and so long service life in order to prevent the financial and social losses by reducing the renewal frequency.

In this study, attempts to enhance the modulus of the rubber bearing compound were made for our country. For this purpose, the selected reference rubber bearing compound was reinforced with chopped and sized carbon fiber. Furthermore, the base rubber (natural rubber, NR) of the reference compound were blended with epoxidized natural rubber (ENR) and blends were evaluated in terms of rheological, mechanical and aging properties.

ENR is produced by controlled chemical modification of NR with acetic acid or peroxy formic acid (Figure 1). During epoxidation process, the number of NR that forms epoxy structure indicates the level of epoxidation, and $10 \%, 25 \%$ and $50 \%$ mole percent epoxy containing ENR are produced commercially as ENR-10, ENR-25 and ENR-50, respectively. Oil resistance and gas permeability properties of ENR are superior againist natural rubber due to random arrangement of the epoxy groups on the main chain of the polymer [4-6]. Besides, epoxy groups are on main chain of the polymer provides only a slight deterioration in mechanical and thermal properties of the rubber.

*Corresponding Author: bkaraagac@kocaeli.edu.tr 


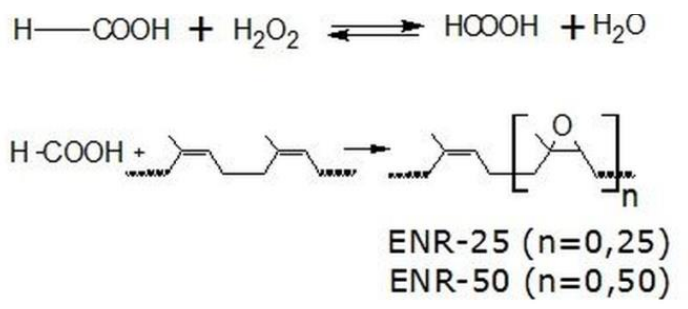

Figure 1. In-situ ENR synthesis reaction (by peroxy formic acid) [4]

Carbon fiber (CF), which contains $92 \%$ by weight carbon, is a high strength material and may be used as chopped short fibers or as continuous form. Poly(acrylonitrile) (PAN) or tar is used as precursor for producing continuous as well as chopped carbon fibers, commercially [7]. Carbon fiber reinforced polymeric composites find widespread use in aviation, automotive, sports, and other industries due to excellent properties such as high strength, high modulus, low density and relatively low cost. Besides, they are frequently essential components of aerospaces thanks to high temperature resistance.

When load is applied to carbon fiber reinforced composites, the tension is transmitted from one fiber to another via the matrix structure. If the interaction between the fiber and the matrix is not enough, the composite material exhibits lower mechanical properties than expected. This problem is generally tried to be overcomed by fiber surface treatment (sizing). However, by excessively strong interaction between matrix and fiber, composite material may become more fragile and weaker. Therefore, it is very important to apply the appropriate level of sizing to fibers. There have been many attempts made to enhance the interaction between the matrix and sized fiber. As a result of modification, functional groups such as $-\mathrm{OH},=\mathrm{O},=\mathrm{C}=\mathrm{O},-\mathrm{COOH},-\mathrm{CO}_{3}$ are generated on the surface to interact with the matrix, thereby improved the mechanical properties of the composite [7, 8]. Sizing agents are expected to chemically bond both carbon fiber and the polymeric matrix for sufficient reinforcement. When the epoxy based sizing, which involves epoxy and amine groups, is considered, it binds to functional groups on the fibers. In case of polyamide sizing, fiber surface interacts with carboxylic acid groups [7].

Chopped carbon fibers sized with various sizing agents such as polyurethane based, phenoxy based, epoxy based, polyamides based and hydrocarbon based, are available in the market. By this means, it is possible to use alternative compatible fiber for different polymeric matrices. Using carbon fiber as a reinforcing material in the thermosetting resins and in thermoplastics is quite common $[8,9]$. However, elastomeric material reinforcement with carbon fiber is not as widespread as other matrices; also there are some important studies about carbon fiber reinforced rubber materials in literature. Carbon fiber has usually been utilized in elastomeric matrices for improving dynamic-mechanical properties, for increasing electrical conductivity, and as a radiation shieldig material [10-12].

Cataldo et al. [13] studied the alterations in material properties in case of using milled and chopped carbon fiber reinforcement in natural rubber based rubber compounds. New rubber compounds were prepared and characterized after incorporation 2, 4, and $6 \mathrm{phr}$ of carbon fiber and comparison was done between the new compounds and the reference one. Even for $2 \mathrm{phr}$ carbon fiber, a substantial increase in tensile modulus was observed for relatively low strain values. When carbon fiber ratio was increased to $6 \mathrm{phr}$, the tensile modulus for $50 \%$ elongation was approximately doubled. Hysteretic properties of the vulcanizates were also followed through tan $\delta$ measurements. Damping at lower strain values was significantly decreased by carbon fiber incorporation. Same samples were tested by Goodrich flexometer to measure heat build-up property (increase of temperature at the end of the standard test period) for high frequency. Temperature increment results confirmed the reduction in hysteresis losses after carbon fiber incorporation. Carbon fiber loading also reduced the compression set values of material. The only negatively affected property with carbon fiber loading was investigated as tear strength. 
Elastomeric materials are often used as compressed under load in common applications. Therefore, unlike plastics, high compression modulus as well as tensile modulus is advantegeous in the presence of fiber reinforcement. Rios et al [14] studied abrasion, modulus, and hysteresis properties of NR, styrene-butadiene rubber (SBR) and butadiene rubber (BR) based tire tread compounds after fiber reinforcement. Anuar et al. [15] produced short carbon fiber and kenaf fiber reinforced natural rubber based thermoplastic elastomers (TPE) and characterized them in terms of flexural and impact properties. Fiber loading, fiber fraction and the fiber surface treatment were evaluated as variable parameters. Carbon fiber surface was oxidatively modifed before adding to polymeric matrix. Until fiber/polymer ratio is $15 \%$, tensile modulus increased as about 5 times in total. However, for higher fiber loadings, a significant change were not observed in modulus.

Ibarra and Palma [16] investigated the possibility of chemical interaction between chopped oxidized carbon fiber and a polar elastomer such as ENR. For this purpose, the surface of the carbon fiber were oxidized with appropriate methods and carboxyl $(-\mathrm{COOH})$ groups were formed on the surface. $50 \%$ (by mol) epoxidized NR (ENR50) was used as rubber matrix. 10-30 phr fiber containing compounds were prepared; elastic torque $\left(S^{\prime}\right)$ and viscous torque $\left(S^{\prime \prime}\right)$ components were measured by using a moving die rheometer (MDR). Rheometer parameters provided important information about crosslinking reaction. $S^{\prime}$ value was followed to evaluate fiber-matrix interactions. It was concluded that, fiber oxidation considerably enhanced the reaction yield between fiber and rubber matrix, especially for high curing temperatures.

In this study, natural rubber has been reinforced with chopped and hydrocarbon sized carbon fiber. Furthermore, epoxidized natural rubber, which was produced by chemical modification of natural rubber, blended with NR and the compounds have been reinforced with epoxy sized carbon fiber. NR and NR/ENR based rubber compounds' rheological, mechanical, morphological and aging properties have been systematically investigated and evaluated.

\section{MATERIALS AND METHODS}

\subsection{Chemicals}

NR (SVR-3L) was obtaied from Standart Thai Ninh Rubber Group having \%98 cis-1,4-polyisoprene. Plasticity retention index (PRI) is 90 and ash content is $0.2 \%$. Epoxidized natural rubber (ENR-50) was purchased from Tailand Muang Mai Guthrie Public Company. Carbon black (Volgograd N330) has a surface area (STSA) of 76- $88 \mathrm{~m}^{2} / \mathrm{g}$. Process oil (Nytex-840) was purchased from Nynas having a density of $0.9183 \mathrm{~g} / \mathrm{cm}^{3}\left(20^{\circ} \mathrm{C}\right)$, viscosity of $371.60 \mathrm{~mm}^{2} / \mathrm{s}\left(40^{\circ} \mathrm{C}\right)$, and VGC (Viscosity Gravity Constant) value of 0.846 . Hydrocarbon distribution is $12.7 \%$ aromatic, $32.2 \%$ naphthenic, and $55.2 \%$ paraffinic. Sulfur S80 have a sulfur content of $79 \pm 2 \%$ was obtained from Rhein Chemie; zinc oxide in $99.9 \%$ purity was obtained from Metal Oksit (Turkey), and stearic acid with 2-4\% $\mathrm{I}_{2}$ was obtained from Wilmer Nabati, Indonesia. Other compounding ingredients are commercially used additives in tyre and rubber industries and are purchased from Lanxess. Chopped $(6 \mathrm{~mm})$ and sized carbon fibers were obtained from the DowAksa (Turkey). HCF means the sizing material of carbon fiber is hydrocarbon based, and also ECF means epoxy sized carbon fiber.

\subsection{Apparatus and Experimental Procedure}

In the first stage of the study, natural rubber based rubber compounds were reinforced with chopped and hydrocarbon sized carbon fibers in order to provide the high modulus properties. Then, in the second stage, natural rubber was blended with epoxidized natural rubber for enhancing the related properties of NR. NR/ENR based rubber compounds were reinforced with epoxy sized carbon fiber to enhance the high modulus requirements. In this stage, effect of sizing material on the rubber matrix was also evaluated. 
In the first stage, rubber matrix (NR) and other compounding ingredents were kept constant; HCF ratio was altered 0 to $5 \mathrm{phr}$. The first stage formulation details are given in Table 1 . In the second stage, selected CF ratio and compounding ingredients were kept constant; rubber matrix was changed from 100/0 to 75/25 as NR/ENR ratio. Besides, in the second group compounds, sizing material for $\mathrm{CF}$ was selected as epoxy based to provide possibly more strong interaction between the fiber and ENR. NR/ENR compound formulations are shown in Table 2.

Table 1. NR based rubber compound formulations

\begin{tabular}{|l|c|c|c|c|}
\cline { 2 - 5 } \multicolumn{1}{c|}{} & NR & NR-HCF-1 & NR-HCF-3 & NR-HCF-5 \\
\hline & \multicolumn{4}{c|}{ Composition (phr) } \\
\hline NR & 100 & 100 & 100 & 100 \\
\hline CB (N330) & 55 & 55 & 55 & 55 \\
\hline Hydrocarbon sized CF & - & 1 & 3 & 5 \\
\hline Process Oil & 4.92 & 4.92 & 4.92 & 4.92 \\
\hline Activators & 6.23 & 6.23 & 6.23 & 6.23 \\
\hline Stabilizers & 6.56 & 6.56 & 6.56 & 6.56 \\
\hline Curing System & 3.45 & 3.45 & 3.45 & 3.45 \\
\hline
\end{tabular}

Tablo 2. NR/ENR based rubber compound formulations

\begin{tabular}{|l|c|c|c|c|c|c|}
\cline { 2 - 7 } \multicolumn{1}{c|}{} & $\begin{array}{c}\text { ENR-0- } \\
\text { ECF-3 }\end{array}$ & $\begin{array}{c}\text { ENR-1- } \\
\text { ECF-3 }\end{array}$ & $\begin{array}{c}\text { ENR-2- } \\
\text { ECF-3 }\end{array}$ & $\begin{array}{c}\text { ENR-3- } \\
\text { ECF-3 }\end{array}$ & $\begin{array}{c}\text { ENR-4- } \\
\text { ECF-3 }\end{array}$ & $\begin{array}{c}\text { ENR-5- } \\
\text { ECF-3 }\end{array}$ \\
\hline & \multicolumn{7}{c|}{ Composition (phr) } \\
\hline NR & 100 & 95 & 90 & 85 & 80 & 75 \\
\hline ENR & 0 & 5 & 10 & 15 & 20 & 25 \\
\hline CB (N330) & 55 & 55 & 55 & 55 & 55 & 55 \\
\hline Epoxy sized CF & 3 & 3 & 3 & 3 & 3 & 3 \\
\hline Process Oil & 4.92 & 4.92 & 4.92 & 4.92 & 4.92 & 4.92 \\
\hline Activators & 6.23 & 6.23 & 6.23 & 6.23 & 6.23 & 6.23 \\
\hline Stabilizers & 6.56 & 6.56 & 6.56 & 6.56 & 6.56 & 6.56 \\
\hline Curing System & 3.45 & 3.45 & 3.45 & 3.45 & 3.45 & 3.45 \\
\hline
\end{tabular}

Preweighed rubber, fillers, and other materials were respectively loaded and mixed in $4 \mathrm{~L}$ of an internal mixer (banbury) at constant speed $(42 \mathrm{rpm})$ and two-roll mill, subsequently. First of all, natural rubber was masticated in banbury for 2 minutes. Then carbon black, other reinforcing materials and process oil were added to the system in three stages by $30 \mathrm{~s}$ durations and rubber compound was mixed for more 5 minutes. Activators and antidegredants were added and the compound was mixed for 3 minutes more. Rubber compound was taken from banbury at $110^{\circ} \mathrm{C}$. The first stage rubber compound was mixed for about 4 minutes in the two-roll mill and sheeted out. After cooling for 24 hours, curing agents were added on two-roll mill during 6 minutes.

The rheological properties of the compounds were measured by using moving die rheometer (MDR 2000, Alpha Technologies) according to ASTM D5289. Rheometer curves were obtained at $150^{\circ} \mathrm{C}$. Vulcanization were realized on hot press under presure considering the determined optimum cure times of the compounds. Tensile properties of the vulcanizates were measured by using a universal testing machine (Zwick Z0.1TH) with a speed of $500 \mathrm{~mm} / \mathrm{min}$ according to ASTM D412. The machine with extensometer has 8195 pneumatic grips type and the load cell is capable of $1 \mathrm{kN}$ force. Tear strength of the vulcanizates was measured by using the same system at a speed of $200 \mathrm{~mm} / \mathrm{min}$ according to ASTM D5584. Hardness values were obtained in Shore A durometer hardness degree according to ASTM D2240. In compression set test, ability of rubber to recover from a compressive deformation was measured. According to ASTM D395 method, $6 \mathrm{~mm}$ thickness and $50 \mathrm{~mm}$ diameter samples were compressed by $25 \%$ of its original thickness and it was held in this state between two 
steel plates for $24 \mathrm{~h}$ at $25{ }^{\circ} \mathrm{C}$ and also for $70 \mathrm{~h}$ at $70{ }^{\circ} \mathrm{C}$ for each samples. The steel plates were then removed and the thickness was re-measured. The dispersion of the compounds were measured by using $100 \mathrm{x}$ magnification dispergrader (DisperTester3000, Montech) according to ISO 11345. Elasticity of the materials was related with their rebound resilience. Resillience tests were done according to ASTM D7121. Thermal aging was performed in an air circulating oven at $70{ }^{\circ} \mathrm{C}$ for 7 days according to ASTM D573. Tensile and hardness measurements were also repeated after aging. Changes in the properties were evaluated for defining aging characteristics of the vulcanizates. All rheological, morphological and mechanical measurements were done with least for five samples from different parts of the material and average values were reported.

\section{RESULTS AND DISCUSSION}

\section{1. NR Compounds Reinforced with Hydrocarbon Sized Carbon Fibers}

In the first stage of the study, natural rubber based rubber compounds were reinforced with chopped and hydrocarbon sized carbon fibers in order to provide the high modulus properties. Rheometer curves of the HCF reinforced natural rubber compounds were shown in Figure 2 and important rheological characteristics were given in Table 3.

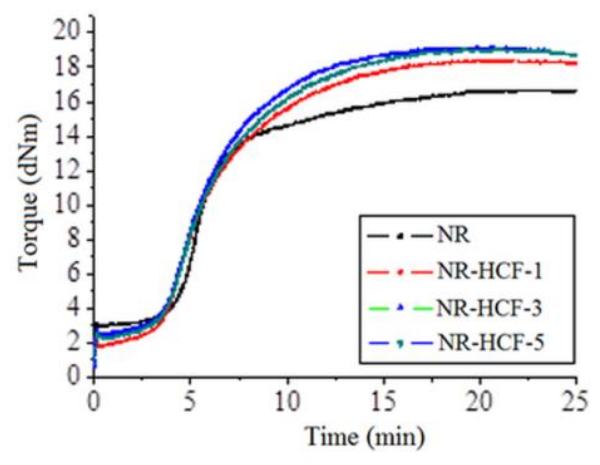

Figure 2. Rheometer curves of NR and NR/HCF based rubber compounds at $150^{\circ} \mathrm{C}$

Table 3. Rheological properties of NR and NR/HCF based rubber compounds

\begin{tabular}{|c|c|c|c|c|}
\hline & NR & NR-HCF-1 & NR-HCF-3 & NR-HCF-5 \\
\hline Rheometer temperature & \multicolumn{4}{|c|}{$150^{\circ} \mathrm{C}$} \\
\hline $\mathrm{M}_{\mathrm{L}}(\mathrm{dNm})$ & 2.01 & 1.80 & 2.50 & 2.32 \\
\hline $\mathrm{M}_{\mathrm{H}}(\mathrm{dNm})$ & 16.50 & 18.32 & 19.10 & 18.83 \\
\hline $\mathrm{t}_{\mathrm{s} 2}(\min )$ & 3.84 & 3.86 & 3.89 & 3.95 \\
\hline$t_{90}(\min )$ & 11.77 & 11.65 & 11.17 & 11.81 \\
\hline Cure extent $(\mathrm{dNm})$ & 14.49 & 16.50 & 16.6 & 16.52 \\
\hline Cure rate index (CRI) & 12.61 & 12.84 & 13.74 & 12.72 \\
\hline $\tan \delta @ \mathrm{MH}_{\mathrm{H}}$ & 0.15 & 0.13 & 0.16 & 0.13 \\
\hline
\end{tabular}

There is no significant change in processability of the compounds observed by incorporating carbon fiber. An important finding on rheological properties of CF containing compounds is higher cure extent values that represent higher cross linking degree during cure reaction. However, there is not a systematic increase in this value for different $\mathrm{CF}$ loadings. Use of carbon fiber did not cause a reduction in scorch time, and also in cure rate index of NR. In summary, CF incorporation has not a deteriorating effect on rheological properties, but also gives higher cure extent in advantageous manner. Before and after aging physical and mechanical properties of NR vulcanizates are given in Table 4 and Table 5, respectively. 
Table 4. Mechanical properties of NR and NR/HCF based rubber compounds

\begin{tabular}{|l|c|c|c|c|}
\hline & NR & NR-HCF-1 & NR-HCF-3 & NR-HCF-5 \\
\hline Curing temperature & $150{ }^{\circ} \mathrm{C}$ & \multicolumn{3}{|l|}{} \\
\hline Tensile strength (MPa) & 22.26 & 22.04 & 20.28 & 20.14 \\
\hline Elongation at break (\%) & 551 & 472 & 455 & 425 \\
\hline $50 \%$ Modulus (MPa) & 1.21 & 1.50 & 1.86 & 2.23 \\
\hline $100 \%$ Modulus (MPa) & 2.13 & 2.67 & 2.87 & 3.37 \\
\hline Hardness (Shore A) & 62.8 & 64.8 & 69.9 & 70.6 \\
\hline Tear strength (N/mm) & 25.12 & 20.53 & 23.90 & 21.02 \\
\hline Elasticity (\%) & 43.6 & 46.8 & 42.6 & 45.2 \\
\hline
\end{tabular}

Table 5. Mechanical properties after aging of NR and NR/HCF based vulcanizates

\begin{tabular}{|l|c|c|c|c|}
\hline & NR & NR-HCF-1 & NR-HCF-3 & NR-HCF-5 \\
\hline Aging conditions & $70{ }^{\circ} \mathrm{C}-7$ days & 18.28 & 19.57 \\
\hline Tensile strength (MPa) & 22.23 & 20.20 & 400 & 391 \\
\hline Elongation at break (\%) & 446 & 447 & 2.26 & 2.50 \\
\hline $50 \%$ Modulus (MPa) & 1.56 & 1.70 & 3.45 & 3.74 \\
\hline $100 \%$ Modulus (MPa) & 2.96 & 2.91 & 72.9 & 72.8 \\
\hline Hardness (Shore A) & 65.3 & 66.0 & 23.8 & 13.15 \\
\hline Tear strength (N/mm) & 17.67 & 16.31 & 22.9 & 23.89 \\
\hline Compression set (@70 $\left.{ }^{\circ} \mathrm{C}-24 \mathrm{~h}\right)(\%)$ & 22.23 & 22.08 & \\
\hline
\end{tabular}

It is clearly seen from Table 4 that, carbon fiber reinforcement provided 20-85\% increase in modulus. Impressive increase in modulus values, which is important for especially target bearing applications, is quite closed for 3 and $5 \mathrm{phr}$ CF incorproration. If we evaluate the two compounds, NR-HCF-3 receipt seems to be better due to its lower deterioration in tear strength value, lower permanent deformation and also competitive cost; so later studies on NR/ENR compounds were built on $3 \mathrm{phr} C F$ reinforcement.

In order to relate the morphological properties with the mechanical behavior of the NR-HCF compounds, dispersion analysis was done for NR, NR-HCF-1, NR-HCF-3, and NR-HCF-5 vulcanizates. In this method, sample data is automatically compared to standard dispersion scale of 1 to 10 . The DisperTerster uses digital image processing to automatically measure the size and proportion of undispersed agglomerates and provides an optical and quantitative comparison of results. The agglomerate rating are on a scale of 1 to 10 gives an indication of the number of agglomerates (y) and size of agglomerates (x). The system also defines the degree of dispersion in terms of percentage, comparing the standard dispersion scales. $\mathrm{x}, \mathrm{y}$, and percentage dispersion quality are given in Table 6 for NR, NR-HCF-1, NR-HCF-3, and NR-HCF-5. Dispersion images of the same vulcanizates are also given in Figure 3.

Table 6. Dispersion parameters of NR and NR/HCF based rubber compounds

\begin{tabular}{|l|c|c|c|c|}
\hline & NR & NR-HCF-1 & NR-HCF-3 & NR-HCF-5 \\
\hline $\mathrm{x}$ & 6.61 & 2.61 & 1.48 & 1.00 \\
\hline $\mathrm{y}$ & 9.70 & 7.89 & 6.43 & 4.06 \\
\hline Dispersion (\%) & 95.65 & 75.45 & 56.63 & 28.15 \\
\hline
\end{tabular}



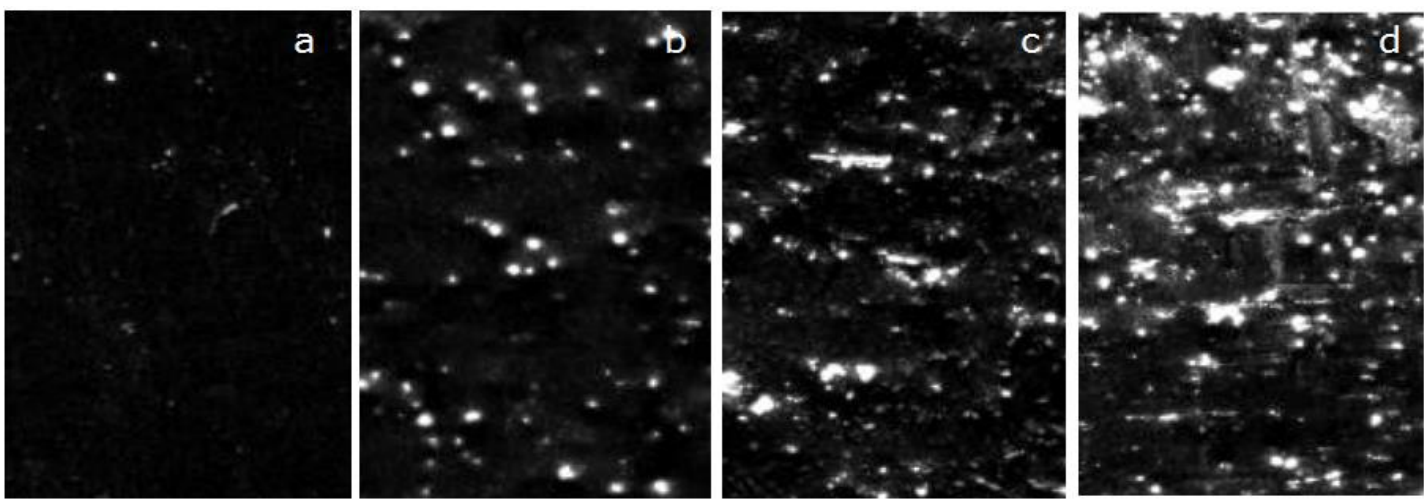

Figure 3. Dispersion images of NR based vulcanizates ( a) NR, b) NR-HCF-1, c) NR-HCF-3, d) NR-HCF-5

As it is seen from Figure 3, dispersion quality of the vulcanizates tends to deteriorate by further CF incorporation. Degree of deterioration is also evident in Table 6, considering size and number of agglomerates and percentage state of dispersion. Decrease in tear strength of aged and unaged vulcanizates can be attributed to relatively bigger agglomerates in NR-HCF-5 compound. In conclusion, morphological findings support that $3 \mathrm{phr}$ is the most appropriate $\mathrm{CF}$ amount for the ongoing studies (next compound group).

\subsection{NR/ENR Compounds Reinforced with Epoxy Sized Carbon Fibres}

In the second stage of the study, NR was partially replaced by ENR in the blend as 5-25 phr. Also, sizing material for CF was selected as epoxy based to provide possibly more strong interaction between the fiber and ENR. Rheometer curves of NR/ENR based rubber compounds were given in Figure 4; some important rheological properties were also given in Table 7.

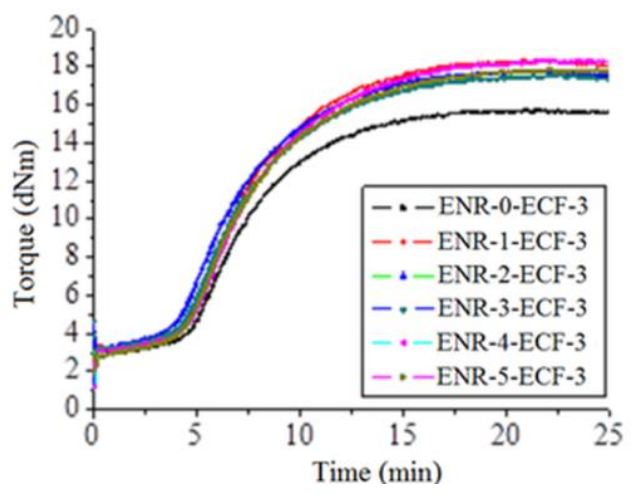

Figure 4. Rheometer curves of NR/ENR based rubber compounds at $150^{\circ} \mathrm{C}$

Table 7. Rheological properties of NR/ENR and ECF based rubber compounds

\begin{tabular}{|l|c|c|c|c|c|c|}
\hline & $\begin{array}{c}\text { ENR-0- } \\
\text { ECF-3 }\end{array}$ & $\begin{array}{c}\text { ENR-1- } \\
\text { ECF-3 }\end{array}$ & $\begin{array}{c}\text { ENR-2- } \\
\text { ECF-3 }\end{array}$ & $\begin{array}{c}\text { ENR-3- } \\
\text { ECF-3 }\end{array}$ & $\begin{array}{c}\text { ENR-4- } \\
\text { ECF-3 }\end{array}$ & $\begin{array}{c}\text { ENR-5- } \\
\text { ECF-3 }\end{array}$ \\
\hline Rheometer temperature & $150^{\circ} \mathrm{C}$ \\
\hline $\mathrm{M}_{\mathrm{L}}(\mathrm{dNm})$ & 3.03 & 3.29 & 3.29 & 3.09 & 2.94 & 2.84 \\
\hline $\mathrm{M}_{\mathrm{H}}(\mathrm{dNm})$ & 15.72 & 18.28 & 17.69 & 17.45 & 18.11 & 17.85 \\
\hline $\mathrm{t}_{\mathrm{s} 2}(\mathrm{~min})$ & 5.14 & 4.83 & 4.38 & 4.65 & 4.88 & 4.71 \\
\hline $\mathrm{t} 90(\mathrm{~min})$ & 12.52 & 12.95 & 12.38 & 12.96 & 13.45 & 13.17 \\
\hline Cure extent $(\mathrm{dNm})$ & 12.69 & 14.99 & 14.4 & 14.36 & 15.17 & 15.01 \\
\hline Cure rate index $(\mathrm{CRI})$ & 13.55 & 12.32 & 12.50 & 12.03 & 11.67 & 11.82 \\
\hline $\tan \delta @ \mathrm{M}_{\mathrm{H}}$ & 0.139 & 0.078 & 0.076 & 0.073 & 0.072 & 0.072 \\
\hline
\end{tabular}


In this group of compounds, the fundamental differences in rheological properties are longer curing times, higher cure extent, and also especially considerable decrease in tan $\delta$ vales for ENR containing compounds. Lower cure rate index and higher indicate epoxy ring of ENR to change the vulcanization reaction mechanism as also seen from the rheometer curves (Figure 4). Higher elasticity can be attributed to higher free chain end concentration in the vulcanizates due to stopped epoxy radicals in vulcanization media. Previous observations about change in vulcanization mechanism are also be validated by higher elasticity.

Physical and mechanical properties of the vulcanizates before and after aging were given in Table 8 and Table 9, respectively. Epoxy sized carbon fiber reinforcement has enhanced tensile modulus values in ENR containing vulcanizates. If we compare the modulus for NR-HCF-3 with ENR-4-ECF3 and ENR-5-ECF-3, that can be seen improved modulus values. Tear strength of vulcanizates are considerably higher (as 24-65\%) in case of NR/ENR rubber matrix. Rebound resilience of the vulcanizates has also been improved slightly in NR/ENR vulcanizates compared to that of NR vulcanizates. However, tensile strength and elongation at break changes of ENR containing vulcanizates are a bit more sensitive to thermal aging. This behaviour may be attributed to increased reactivity of NR main chain due to epoxy functional groups.

Table 8. Mechanical properties of NR/ENR based rubber compounds

\begin{tabular}{|l|c|c|c|c|c|c|}
\hline & $\begin{array}{c}\text { ENR-0- } \\
\text { ECF-3 }\end{array}$ & $\begin{array}{c}\text { ENR-1- } \\
\text { ECF-3 }\end{array}$ & $\begin{array}{c}\text { ENR-2- } \\
\text { ECF-3 }\end{array}$ & $\begin{array}{c}\text { ENR-3- } \\
\text { ECF-3 }\end{array}$ & $\begin{array}{c}\text { ENR-4- } \\
\text { ECF-3 }\end{array}$ & $\begin{array}{c}\text { ENR-5- } \\
\text { ECF-3 }\end{array}$ \\
\hline Curing temperature & $150^{\circ} \mathrm{C}$ \\
\hline Tensile strength (MPa) & 22.25 & 21.50 & 20.30 & 21.20 & 20.50 & 20.90 \\
\hline Elongation at break (\%) & 491 & 488 & 468 & 498 & 465 & 467 \\
\hline 50\% Modulus (MPa) & 1.90 & 2.25 & 1.70 & 1.90 & 2.65 & 2.15 \\
\hline 100\% Modulus (MPa) & 2.80 & 3.30 & 2.95 & 3.15 & 4.10 & 3.55 \\
\hline Hardness (Shore A) & 69.5 & 73.0 & 71.5 & 72.0 & 72.5 & 73.0 \\
\hline Tear strength (N/mm) & 31.20 & 32.60 & 30.63 & 30.40 & 32.00 & 34.45 \\
\hline Elasticity (\%) & 47.1 & 50.2 & 49.6 & 51.3 & 51.6 & 52.0 \\
\hline
\end{tabular}

Tablo 9. Mechanical properties of NR/ENR based vulcanizates after aging

\begin{tabular}{|l|c|c|c|c|c|c|}
\hline & $\begin{array}{c}\text { ENR- } \\
\mathbf{0 -}\end{array}$ & $\begin{array}{c}\text { ENR-1- } \\
\text { ECF-3 }\end{array}$ & $\begin{array}{c}\text { ENR-2- } \\
\text { ECF-3 }\end{array}$ & $\begin{array}{c}\text { ENR-3- } \\
\text { ECF-3 }\end{array}$ & $\begin{array}{c}\text { ENR-4- } \\
\text { ECF-3 }\end{array}$ & $\begin{array}{c}\text { ENR-5- } \\
\text { ECF-3 }\end{array}$ \\
\hline Aging conditions & $70^{\circ} \mathrm{C}-7$ days \\
\hline Tensile strength (MPa) & 21.80 & 22.50 & 19.70 & 20.90 & 21.25 & 20.05 \\
\hline Elongation at break (\%) & 443 & 429 & 419 & 424 & 431 & 409 \\
\hline 50\% Modulus (MPa) & 2.35 & 3.10 & 2.20 & 2.40 & 2.90 & 2.75 \\
\hline 100\% Modulus (MPa) & 3.85 & 4.45 & 3.90 & 3.85 & 4.65 & 4.60 \\
\hline Hardness (Shore A) & 71.0 & 74.5 & 74 & 73.5 & 74.90 & 75.0 \\
\hline Tear strength (N/mm) & 21.43 & 14.77 & 17.22 & 28.54 & 15.98 & 24.41 \\
\hline $\begin{array}{l}\text { Compression set (@70 } \\
(\%)\end{array}$ & 12.02 & 11.97 & 9.10 & 9.29 & 9.93 & 9.69 \\
\hline
\end{tabular}

\section{CONCLUSIONS}

This study has been designed as two stages. In the first stage, natural rubber has been reinforced with chopped and hydrocarbon sized carbon fiber. In the second stage, natural rubber was blended with epoxidized natural rubber and reinforced with chopped and epoxy sized carbon fiber. Rheological properties of both stages have been improved in terms of cure extent. High tensile modulus, which is the target improvement due to carbon fiber reinforcement, has been obtained by using the optimum fiber ratio ( $3 \mathrm{phr})$ and the exact sizing material. Considerably improved tear strength values were provided in case of ENR incorporation to NR. Furthermore, improved elasticity and rebound 
Yeşil and Karaăgaç / Anadolu Univ. J. of Sci. and Technology - A-Appl. Sci. and Eng. 17 (5) - 2016

resilience properties are additional advantages for NR/ENR blends due to higher free chain end concentration in the vulcanizates due to stopped epoxy radicals in vulcanization media.

\section{ACKNOWLEDGEMENTS}

Authors greatfully thank to TÜBİTAK TEYDEB for their valuable supports in research project 3130683.

\section{REFERENCES}

[1] Vahapoğlu V. Rubber-like materials: Classification. Mehmet Akif Ersoy University Institute of Science and Technology Journal 2013; 4(1):25-34.

[2] Erkek S. The effect of carbon black/oil and carbon black/filler ratio on the physico mechanical Properties of EPDM, NBR and SBR elastomers at different vulcanization systems. MSc, University of Çukurova, Adana, 2007.

[3] Kamarah SR. Effect of natural filler on the characterization of natural rubber. Bachelor, University of Malaysia Pahang, Malaysia, 2010.

[4] Tanjung FA, Hassan A, Hasan M. Use of epoxidized natural rubber as a toughening agent in plastics. J Appl Polym Sci 2015;132(29):42270-42279.

[5] Mascia L,Clarke J, Chua KS, Russo P. Cure efficiency of dodecyl succinic anhydride as a crosslinking agent for elastomer blends based on epoxidized natural rubber. J Appl Polym Sci 2015; 132(6):41448-41457.

[6] Hoon TC. Epoxidized natural rubber (ENR-50) stabilized gold and platinum organosols. MSc, University of Sainsi, Malaysia, 2006.

[7] Chung, DDL. Carbon fiber composites. Washington, USA: Butterworth-Heinemann, 1994.

[8] Morgan P. Carbon fibers and their composites. Florida, USA: CRC Press, 2005.

[9] Richard P, Prasse T, Cavaille JY, Chazeau L, Gauthier C, Duchet J. Reinforcement of rubbery epoxy by carbon nanofibers. Mater Eng Sci 2003; 352(1-2):344-348.

[10] Sau KP, Chaki TK, Chacraborty A, Khastgir D. Electromagnetic interference shielding by carbon black and carbon fiber filled rubber composites. Plast Rubber Compos Process Appl 1997; 26(7): 291-297.

[11] Das NC, Chaki TK, Khastgir D, Chacraborty A. Electromagnetic interference shielding effectiveness of conductive carbon black and carbon fiber filled composites based on rubber and rubber blends. Polym Technol 2001; 20(3): 226-236.

[12] Das NC, Chaki TK, Khastgir D. Effect of axial streching on electrical resistivity of short carbon fibre and carbon black filled conductive rubber composites. Polym Int 2002; 51(2):156-163.

[13] Cataldo F. Study on the reinforcing effect of milled carbon fibers in a natural rubber based composite. J Macromol Sci B 2008; 47(4): 818-828. 
Yeşil and Karaağaç / Anadolu Univ. J. of Sci. and Technology - A - Appl. Sci. and Eng. 17 (5) - 2016

[14] Rios S, Chicurel R, Del Castillo LF. Potential of fibre and particle reinforcement of Tyre tread elastomers. Mater Design 2001; 22(5): 369-374.

[15] Anuar H, Ahmad SH, Rashid R, Ahmad A, Wan Busu WN. Mechanical properties and dynamic mechanical analysis of thermoplastic natural rubber reinforced short carbon fiber and kenaf fiber hybrid composites. J Appl Polym Sci 2008; 107(6): 4043-4052.

[15] Ibarra L, Palma E. Reactivity of short oxidized carbon fibres and functionalized elastomer. Polym Int 1998; 47(3): 361-366. 